\title{
Qualidade físico-química e química de frutos de clones de aceroleira recobertos com filme de PVC e conservados por refrigeração
}

\section{Physico-chemical and chemical quality of acerola fruit clones coated with PVC film and conserved under refrigeration}

\author{
Paolo Germanno Lima de Araújo ${ }^{1}$; Raimundo Wilane de Figueiredo ${ }^{1 *}$ \\ Ricardo Elesbão Alves²; Geraldo Arraes Maia'; \\ Carlos Farley Herbster Moura ${ }^{2}$; Paulo Henrique Machado de Sousa ${ }^{1}$
}

\begin{abstract}
Resumo
Este trabalho objetivou avaliar as mudanças físicas, físico-químicas e químicas em frutos de clones de aceroleira recobertos com filme de PVC e conservados sob refrigeração. Os clones 235 (Apodi), BRS 236 (Cereja), BRS 237 (Roxinha), BRS 238 (Frutacor), II 47/1 e BRS 152 (Sertaneja) foram colhidos no estádio de maturação comercial. Os frutos foram lavados em água clorada, embalados em bandejas de poliestireno expandido cobertos com filme PVC e armazenados $\left(10^{\circ} \mathrm{C}\right)$ durante 12 dias, com retiradas de amostras no início do experimento e a cada três dias. Foram avaliados: coloração, sólidos solúveis totais, acidez titulável, relação sólidos solúveis totais:acidez titulável, $\mathrm{pH}$, açúcares solúveis totais, vitamina $\mathrm{C}$, antocianinas, perda de massa, firmeza e carotenóides. $\mathrm{O}$ experimento foi realizado em delineamento experimental inteiramente casualizado em esquema fatorial (clones $\mathrm{x}$ tempo), com 3 repetições (bandejas com 100g de frutos). Dentre os clones estudados, o II47/1 se destacou pela relativa estabilidade da cor, ângulo hue e teor de antocianinas, sendo mais atrativo para o consumidor na hora da compra. Entretanto os clones Roxinha e Sertaneja apresentaram relação sólidos solúveis totais:acidez titulável superior aos demais no final do experimento, característica interessante para o sabor.

Palavras-chave: Acerola, Malpighia emarginata D.C, vitamina C, carotenóides, antocianinas, firmeza
\end{abstract}

\begin{abstract}
This work aimed to evaluate the physical, physicochemical and chemical changes in fruits of clones of acerola coated with PVC film and conserved under refrigeration. The clones BRS 235 (Apodi), BRS 236 (Cereja), BRS 237 (Roxinha), BRS 238 (Frutacor), II 47/1 and BRS 152 (Sertaneja) had been harvested in the stage of commercial maturation. The fruits had been washed in chlorinated water, packed in expanded polystyrene trays, covered with film PVC and stored $\left(10^{\circ} \mathrm{C}\right)$ during 12 days, with withdrawals of samples at the beginning of the experiment and to each three days. They had been evaluated: coloration, soluble solids, titratable acidity, soluble solids:titratable acidity relation, $\mathrm{pH}$, soluble sugars, vitamin $\mathrm{C}$, anthocyanins, weight lost, firmness and carotenoids. The experiment was carried through in experimental delineation completely randomized in factorial design (clones $\mathrm{x}$ time), with 3 repetitions (trays with $100 \mathrm{~g}$ of fruits). Between the clones studied the II $47 / 1$ if it detached for the relative stability of the color, angle hue, and of anthocyanins, being more attractive for the consumer in the time of the purchase. However the clones Roxinha and Sertaneja had presented superior soluble solids:titratable acidity between the others in the end of the experiment, interesting characteristic for the flavor.
\end{abstract}

Key words: Acerola, Malpighia emarginata D.C, vitamin C, carotenoids, anthocyanins, firmness.

1 Departamento de Tecnologia de Alimentos, Centro de Ciências Agrárias da Universidade Federal do Ceará, Campus do Pici, s/n, CP 12168, CEP 60356-000 Fortaleza - CE, Brasil, E-mail: figueira@ufc.br

2 Embrapa Agroindústria Tropical, Rua Dra. Sara Mesquita, 2270 - Planalto do Pici, CEP 60511-110 - Fortaleza - CE, Brasil, E-mail: elesbao@pesquisador.cnpq.br

* Autor para correspondência 


\section{Introdução}

A acerola (Malpighia emarginata D. C.), conhecida por apresentar altos teores de vitamina $\mathrm{C}$, tem crescido em importância no Nordeste brasileiro, sendo considerada uma das mais importantes fontes desta vitamina; além da presença de outros compostos com propriedades antioxidantes, como carotenóides e fenólicos, a coloca em lugar de destaque entre as frutas (LIMA et al., 2005).

A acerola classificada como um fruto climatérico que passa por uma série de alterações durante os processos de maturação, amadurecimento e senescência, destacando-se degradação da clorofila, síntese dos carotenóides e das antocianinas, decréscimo na acidez, acentuada perda de vitamina $\mathrm{C}$ ao longo desses estádios. Estas podem acontecer quando o fruto está na planta ou após a colheita, podendo ser colhidos no início da maturação (verde, verde-amarelado ou até início da pigmentação vermelha), quando se destinam à produção de vitamina C (ALVES; CHITARRA; CHITARRA, 1995).

A alta taxa respiratória acelera esse processo e encurta o período de tempo com qualidade adequada para o seu aproveitamento como alimento (CHITARRA; CHITARRA, 2005; REINHARDT; OLIVEIRA, 2003). A composição química dos frutos de aceroleira depende da espécie, localização do plantio, fertilização, condições do meio ambiente e do estádio de maturação dos frutos (LIMA et al., 2005).

O uso de tecnologias como refrigeração associada à atmosfera modificada tem a finalidade de manter a qualidade de frutos durante o armazenamento, principalmente os de alta perecibilidade, como a acerola. $\mathrm{O}$ armazenamento refrigerado prolonga o período de comercialização da fruta fresca, porém não evita alterações físico-químicas, que depreciam sua qualidade (CARVALHO; MANICA, 1994). Chitarra e Chitarra (2005) citam que no armazenamento em atmosfera modificada, a atmosfera ambiental é geralmente alterada pelo uso de filmes plásticos, permitindo que a concentração de $\mathrm{CO}_{2}$ proveniente do próprio produto aumente, e as concentrações de $\mathrm{O}_{2}$ diminua, à medida que é utilizado pelo processo respiratório. $\mathrm{O}$ uso de temperaturas baixas regula as taxas de todos os processos fisiológicos e bioquímicos associados com a redução da respiração, há diminuição na perda de aroma, sabor, textura, cor e demais atributos de qualidade dos produtos. Segundo Alves et al. (2003), o uso de filmes plásticos, à base de polietileno ou cloreto de polivinila (PVC), pela sua praticidade, custo relativamente baixo e alta eficiência, têm sido utilizados em associação ao armazenamento refrigerado para evitar perdas, possibilitando com que, através da modificação da atmosfera, frutos tropicais de alta perecibilidade, tenham a sua vida pós-colheita prolongada.

Acerolas colhidas na maturidade fisiológica e armazenadas, em bandejas de poliestireno expandido, sob refrigeração $\left(8{ }^{\circ} \mathrm{C}\right)$ associada à atmosfera modificada por filme de PVC, tiveram o período de vida útil pós-colheita aumentado em uma semana (ALVES; CHITARRA; CHITARRA, 1995). Segundo Reinhardt e Oliveira (2003), estas técnicas associadas poderiam promover uma conservação por um período de até 10 dias. Maciel et al. (2004), em experimento com acerolas armazenadas em 10 e $22{ }^{\circ} \mathrm{C}$ com biofilme, encontraram resultados favoráveis para os frutos armazenados em $10^{\circ} \mathrm{C}$ por até 15 dias. Alves, Chitarra e Chitarra (1995) cita que o armazenamento de frutos de aceroleira sob atmosfera modificada e refrigerados a temperatura de $8{ }^{\circ} \mathrm{C}$ e $85-95 \%$ UR prolongou o tempo de vida útil pós-colheita destes por uma semana, porém, as tecnologias empregadas não foram eficientes na redução das perdas de vitamina C. Guadarrama (1984), estudando as mudanças químicas e atividade respiratória durante o amadurecimento de frutos de aceroleira, armazenados em temperaturas entre 5 e $35^{\circ} \mathrm{C}$, determinou que frutos armazenados nas temperaturas de 10 e $15^{\circ} \mathbf{C}$ foram os que apresentaram melhores condições ao final de 6 a 8 dias de experimento. 
A procura por material de melhor qualidade para plantio tem estimulado alguns pesquisadores e produtores, a procederem a seleção fenotípica individual em suas plantações. Essas ações têm contribuído para a formação de diversos clones de acerola (MOURA et al., 2007). A partir da seleção de plantas com estas características, os programas de melhoramento genético têm sido incrementados através da introdução de novos clones. Atualmente, novos padrões de qualidade são introduzidos, dando maior ênfase ao valor nutritivo destes frutos (AGUIAR, 2001).

O objetivo deste trabalho foi avaliar a conservação dos clones de aceroleiras BRS 152, BRS 235, BRS 236, BRS 237, BRS 238 e II 47/1 recobertos com filmes de PVC e conservados por refrigeração.

\section{Material e métodos}

Ocampo experimental noqual foram selecionados e retirados os frutos dos clones deste experimento foi instalado em agosto de 1999 na Fazenda Frutacor Ltda, no município de Limoeiro do Norte, $\mathrm{CE}$, no delineamento de blocos ao acaso, com 45 tratamentos (clones), três repetições e cinco plantas por parcelas, no espaçamento de $5 \mathrm{~m}$ entre linhas e $4 \mathrm{~m}$ entre plantas. As parcelas foram dispostas em forma linear e a bordadura em torno do experimento foi feita com o clone BRS 237. Os tratamentos foram formados por clones de aceroleira originados da introdução de outras regiões ou obtidos por seleção de plantas no Programa de Melhoramento Genético da Embrapa Agroindústria Tropical. Aárea experimental tem como características topografia plana, altitude de $102 \mathrm{~m}$, solo Cambissolo com $\mathrm{pH}$ de 6,8 e pluviosidade anual média de $772 \mathrm{~mm}$ (PAIVA et al., 2003).

Os frutos selecionados para este experimento foram: BRS 235 - Apodi; BRS 236 - Cereja; BRS 237 - Roxinha; BRS 238 - Frutacor; II 47/1; e BRS 152 - Sertaneja, como testemunha.
Os frutos foram colhidos em outubro de 2004, nas primeiras horas do dia, manualmente, e acondicionados em caixas plásticas forradas com espuma de poliestireno e transportados para o Laboratório de Fisiologia e Tecnologia de PósColheita da Embrapa Agroindústria Tropical, em Fortaleza - Ceará.

Os frutos apresentando coloração verde, iniciando a pigmentação vermelha, de acordo com Alves, Chitarra e Chitarra (1995), foram armazenados em antecâmara a $14{ }^{\circ} \mathrm{C}$ durante duas horas, lavados em água clorada (200 ppm de cloro ativo), secados (no ambiente), embalados em bandeja de poliestireno expandido e recobertos com filme de PVC (cloreto de polivinila), armazenados a $10^{\circ} \mathrm{C}$ durante 12 dias, com embalagem contendo $100 \mathrm{~g}$ de acerolas cada. Avaliações físicas, físico-químicas e químicas foram realizadas no dia da instalação do experimento e a partir daí a cada três dias até o fim do experimento.

\section{Determinações}

\section{Características físicas}

A perda de massa foi feita através de pesagem no início do experimento, em balança semi-analítica (MARK 3100) com precisão de $0,01 \mathrm{~g}$, e a cada tempo de retirada de amostras foram pesadas novamente. Os resultados foram obtidos em \%. A cor Instrumental foi feita por reflectometria, utilizandose de um colorímetro Minolta (Croma Meter CR200b), calibrado em superfície de porcelana branca sob condições de iluminação, sendo expressa no módulo L, C e H (luminosidade, cromaticidade e ângulo Hue, respectivamente). As medições foram feitas tomando-se a região equatorial dos frutos. A firmeza da polpa foi feita através do teste de firmeza (N) em 10 frutos de cada bandeja (100 g de fruto cada) com o auxílio de um penetrômetro manual (FT02) fazendo-se uma punção na região central do fruto. 


\section{Características físico-químicas e químicas}

$\mathrm{O}$ pH foi medido diretamente na polpa, logo após processamento, utilizando-se um potenciômetro (Mettler DL 12) com membrana de vidro, conforme a Association of Official Analytical Chemistry AOAC (1995), aferido com tampões de pH 7 e 4. Obteve-se a acidez total titulável diluindo-se $1 \mathrm{~g}$ de polpa em $50 \mathrm{~mL}$ de água destilada em titulador potenciométrico até $\mathrm{pH} 8,1$ com solução de $\mathrm{NaOH}$ $(0,1 \mathrm{~N})$ e expressa em percentagem de ácido málico, segundo Brasil (2005).

Foi analisado o teor de Vitamina C (mg/100g) titulometricamente com solução de 2,6-diclorofenol-indofenol (DFI) $0,02 \%$ até coloração levemente rósea, utilizando-se uma alíquota de 4,0 $\mathrm{mL}$ proveniente de $1 \mathrm{~g}$ de polpa diluída em $50 \mathrm{~mL}$ de ácido oxálico 0,5\%, de acordo com Brasil (2005).

Os sólidos solúveis totais (SST) foram determinados de acordo com método recomendado pela AOAC (1995), após filtração da polpa em papel de filtro, e leitura ( ${ }^{\circ}$ Brix) em um refratômetro digital de marca Atago PR-101 com escala variando de 0 - $45{ }^{\circ}$ Brix. Obteve-se a relação entre SST e ATT através do quociente entre as duas análises.

Os açúcares solúveis totais foram determinados pelo método da antrona descrita por Yemn e Willis (1954). Foi utilizado $1 \mathrm{~g}$ de polpa dissolvida em $100 \mathrm{~mL}$ de água, sendo a leitura feita em espectrofotômetro (Spectronic Genesys 2) com comprimento de onda de $620 \mathrm{~nm}$ e o resultado expresso em \%.

A determinação de antocianinas totais foi realizada de acordo com o método de Francis (1982), adaptado. Foi feita uma extração através da homogeneização de $1 \mathrm{~mL}$ da amostra com solução de $\mathrm{HCl}(1,5 \mathrm{~N})$ e etanol $85 \%$ durante um período de 16 horas, sob refrigeração $(T=4 \pm 1$ o $C)$ e ao abrigo da luz, sendo os extratos filtrados e então realizada a leitura em espectrofotômetro, com absorbância medida no comprimento de onda de $535 \mathrm{~nm}$. Os resultados expressos em $\mathrm{mg} / 100 \mathrm{~g}$ de polpa e calculados através da fórmula: fator de diluição $\mathrm{x}$ absorbância/98,2.

Os carotenóides totais foram determinados pelo método de Higby (1962), utilizado álcool isopropílico e $2 \mathrm{~mL}$ de hexano para extração dos pigmentos. As leituras foram feitas a $450 \mathrm{~nm}$ e os resultados expressos em $\mathrm{mg} / 100 \mathrm{~g}$.

\section{Delineamento experimental e análises estatísticas}

Foi utilizado delineamento experimental inteiramente casualizado em esquema fatorial $6 \times 5$, tendo como fatores clones etempos, respectivamente, com três repetições.

Os resultados foram avaliados estatisticamente através de análise de variância, verificando interação entre os fatores, o tempo foi desdobrado dentro de cada clone e os resultados submetidos à análise de regressão polinomial. Foram consideradas equações de até $3^{\circ}$ grau. O coeficiente de determinação mínimo para utilização das curvas foi de 0,70 . Foi aplicado teste de Tukey ao nível de 5\% de probabilidade quando conveniente. As análises foram realizadas com auxílio do programa SISVAR versão 3.01.

\section{Resultados e discussão}

\section{Características físicas}

Para os parâmetros físicos, perda de massa, luminosidade, cromaticidade e ângulo Hue foram detectados efeitos significativos $(p \leq 0,05)$ da interação entre os clones de acerola e o tempo de armazenamento. Somente para a firmeza da polpa não foi verificada interação significativa $(p>0,05)$ entre os clones e o tempo de armazenamento, sendo estudados estes efeitos separadamente.

Verificou-se perda gradual da massa em todos os clones estudados, com variação de $0,63 \%$ a 1,62 $\%$, ao final do experimento (Figura 1). Os clones Sertaneja $(0,63 \%)$ e roxinha $(0,71 \%)$ apresentaram os menores valores de perdas de massa, sendo o filme 
de PVC o fator que pode ter contribuído para uma maior estabilidade da massa, já que a diminuição da massa se deve principalmente a perda de água para o meio e o uso de atmosfera modificada diminui a velocidade de perda, pois o filme serve como barreira para a saída de água.

Valores mais elevados de perdas de massa foram encontrados por Alves, Chitarra e Chitarra (1995), $2,15 \%$, em experimento com acerolas armazenadas sob atmosfera modificada e refrigeração $\left(13{ }^{\circ} \mathrm{C}\right)$, após 11 dias de armazenamento, assim como no experimento de Carvalho e Manica (1994), estudando as alterações das características físicas e químicas ocorridas em acerolas verdes, semimaduras e maduras após o armazenamento em temperatura ambiente, refrigerada $\left(5,5\right.$ a $\left.8,0{ }^{\circ} \mathrm{C}\right) \mathrm{e}$ congelamento, a perda de massa foi de 5,2\% após três dias de armazenamento em frutos refrigerados.

A cor do fruto durante o armazenamento varia conforme vai amadurecendo, passando de verde para vermelho no caso da acerola. A coloração é, freqüentemente, um dos atributos de qualidade mais atrativos para o consumidor, e o impacto visual causado pela coloração é fator predominante na preferência do consumidor (BRUNINI et al., 2004).

O clone Cereja foi o que apresentou maior Luminosidade no início do experimento, com ligeiro decréscimo ao final deste, enquanto o Sertaneja permaneceu estável. Os demais clones apresentaram menor Luminosidade desde o início do experimento, permanecendo assim até o final (Figura 2).

$\mathrm{Na}$ Figura 2 observa-se como a intensidade da cor muda nos frutos dos clones estudados. A tendência da intensidade da cor nos clones Apodi, Cereja e Frutacor até o nono dia de armazenamento ocorreu, provavelmente, devido ao amadurecimento do fruto e produção dos pigmentos característicos, enquanto os clones Roxinha, II47/1 e Sertaneja permaneceram estáveis, com ligeiro decréscimo durante o experimento.

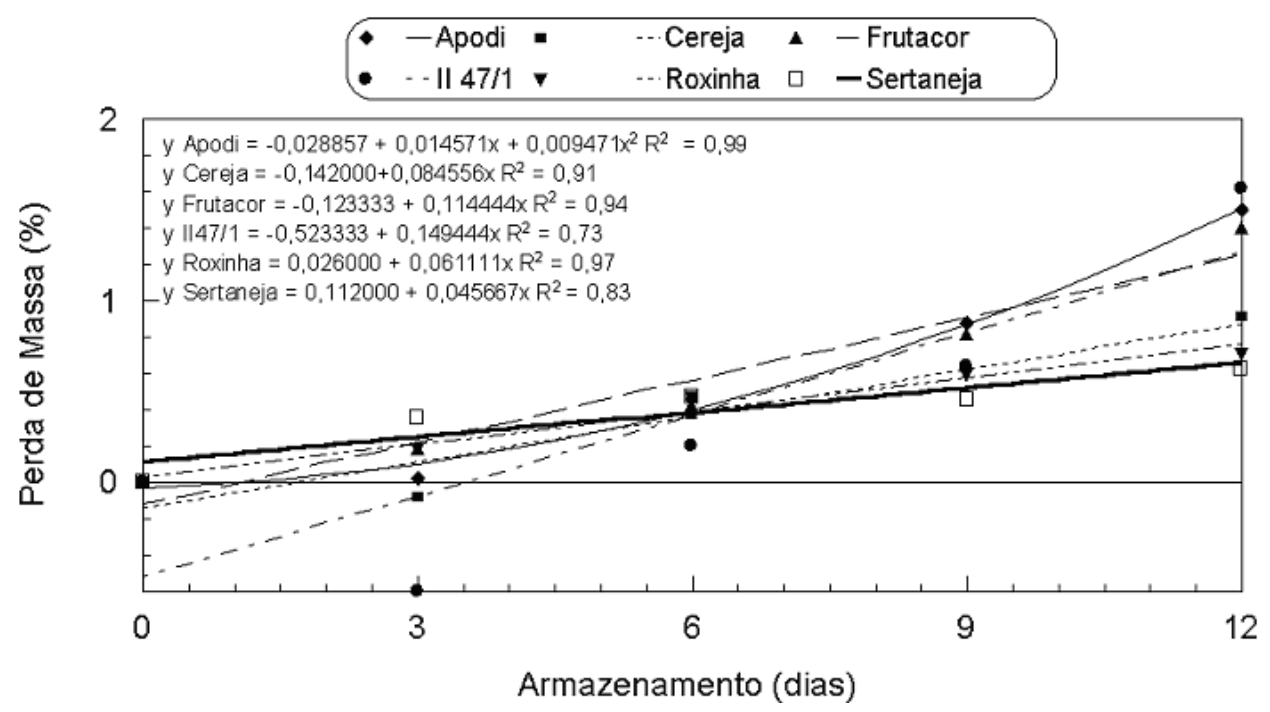

Figura 1. Perda de massa (\%) de frutos de clones de aceroleira recobertos com filme de PVC e armazenados sob refrigeração $\left(10^{\circ} \mathrm{C}\right)$. 

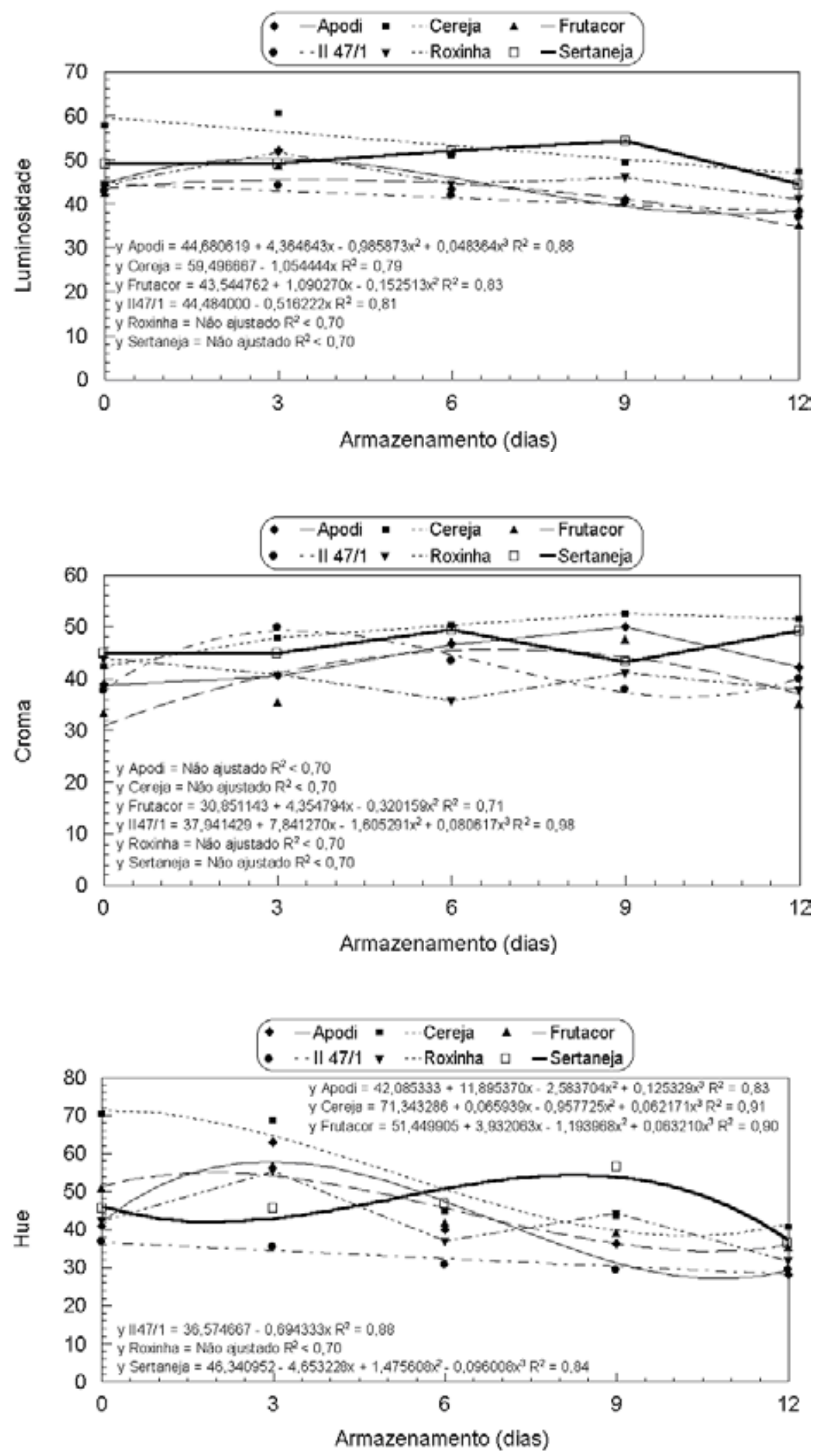

Figura 2. Luminosidade, Cromaticidade e Hue de frutos de clones de aceroleira recobertos com filme de PVC e armazenados sob refrigeração $\left(10^{\circ} \mathrm{C}\right)$. 
A diminuição do ângulo Hue demonstra a mudança de coloração de amarelo para vermelho, que no caso dos frutos de aceroleira, caracteriza o amadurecimento, devido à produção de antocianinas. De um modo geral, todos os clones diminuíram o ângulo Hue durante o armazenamento, com destaque para os clones Cereja e II 47/1, o primeiro devido à diminuição acentuada desta característica até o nono dia de experimento, tornando o fruto avermelhado, bem mais atrativo ao consumo, enquanto o segundo, pela manutenção da coloração desde o início do experimento, com coloração que somente após os 12 dias os outros clones apresentaram (Figura 2).

Foi observada diminuição constante da firmeza durante o armazenamento dos frutos (Figura 3). Segundo Chitarra e Chitarra (2005), no amadurecimento a ação de enzimas como protopectinase, poligalacturonase e pectinametilesterase modificam a firmeza dos frutos, amaciando-os. Outras enzimas também são importantes no amaciamento, a poligalacturonase, encurta a cadeia de pectina, e a pectinametilesterase, desesterifica ou remove os grupos metílico ou acetil do ácido poligalacturônico.

O clone Apodi demonstrou maior valor médio de firmeza $(4,78 \mathrm{~N})$ (Figura 3), não diferindo do clone Roxinha $(4,58 \mathrm{~N})(\mathrm{p}>0,05)$, característica interessante para frutos que serão armazenados, pois assim, provavelmente a manterão durante o período de armazenamento. Os clones Frutacor $(3,80 \mathrm{~N})$, II $47 / 1(4,05 \mathrm{~N})$ e Sertaneja $(3,97 \mathrm{~N})$ foram dentre os estudados, os que apresentaram menor firmeza, não diferindo entre si pelo teste de médias $(\mathrm{p}>0,05)$. Moura et al. (2007), avaliando 45 clones de acerola, encontraram média geral menor para a firmeza $(3,59$ N) que todos os clones avaliados.

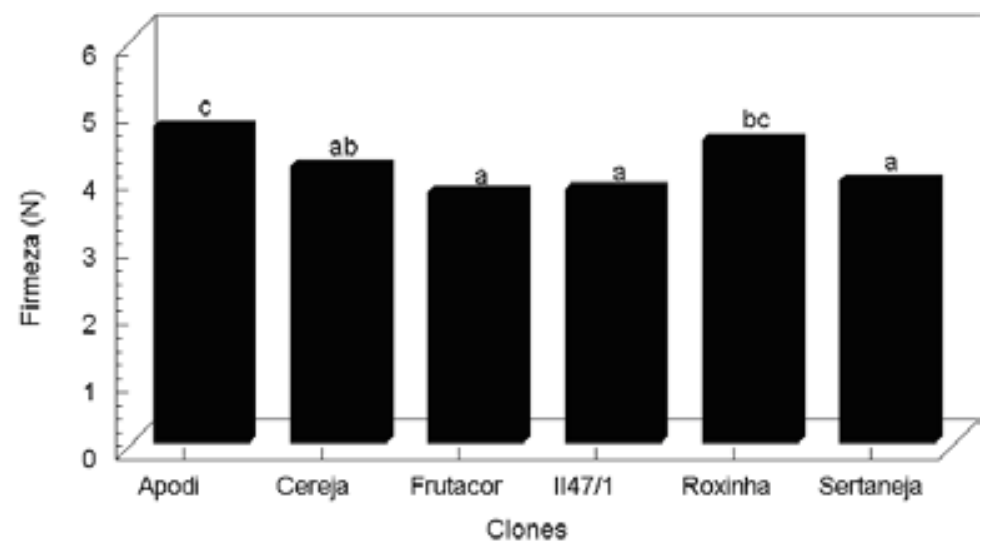

Médias seguidas da mesma letra não diferem pelo teste de Tukey $(\mathrm{p}>0,05)$

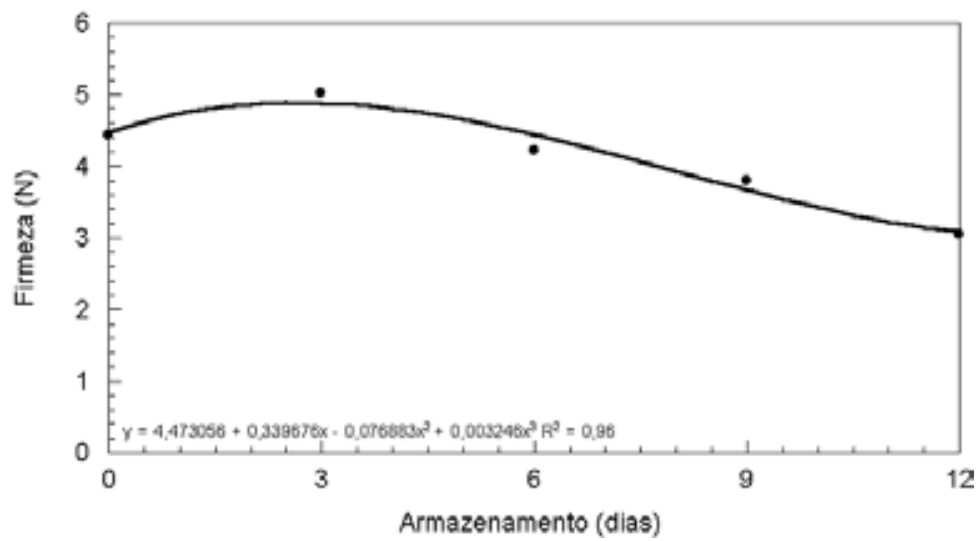

Figura 3. Médias e variações com o armazenamento da firmeza $(\mathrm{N})$ de frutos de clones de aceroleira recobertos com filme de PVC e armazenados sob refrigeração $\left(10^{\circ} \mathrm{C}\right)$. 


\section{Características físico-químicas e químicas}

Os parâmetros acidez total titulável, $\mathrm{pH}$, relação SST/ATT, vitamina $\mathrm{C}$, carotenóides totais e antocianinas totais não apresentaram interação significativa $(p>0,05)$ entre os clones de acerola e o tempo de armazenamento, ou seja, os clones de acerola não foram afetados pelo tempo de armazenamento, sendo estudados os clones separadamente para estes parâmetros; enquanto os sólidos solúveis e os açúcares solúveis apresentaram interação significativa $(\mathrm{p} \leq 0,05)$. Portanto, estudou-se o efeito dos clones através do teste de Tukey para comparação das médias e do tempo de armazenamento nos parâmetros que apresentaram interação significativa e análise de regressão para o restante.

Não foi verificada interação entre os fatores clone $\mathrm{x}$ tempo quanto à determinação de sólidos solúveis totais, entretanto, foi percebida pequena diminuição do teor de SST a partir do sexto dia de armazenamento (Figura 4). Entre os clones houve diferença significativa $(\mathrm{p}<0,05)$, sendo os clones Apodi (7,1 ${ }^{\circ}$ Brix), Cereja (6,8 ${ }^{\circ}$ Brix), Frutacor $\left(6,9^{\circ}\right.$ Brix $)$ e II $47 / 1\left(7,1^{\circ}\right.$ Brix $)$ superiores estatisticamente aos demais (Figura 4).

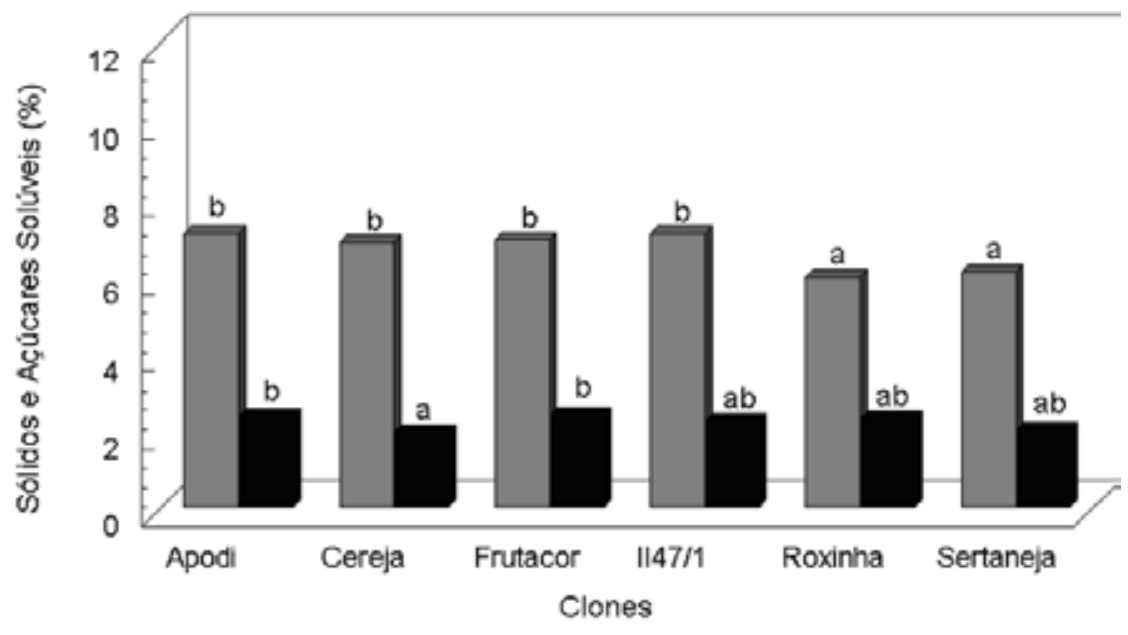

Médias seguidas da mesma letra não diferem pelo teste de Tukey $(\mathrm{p}<0,05)$

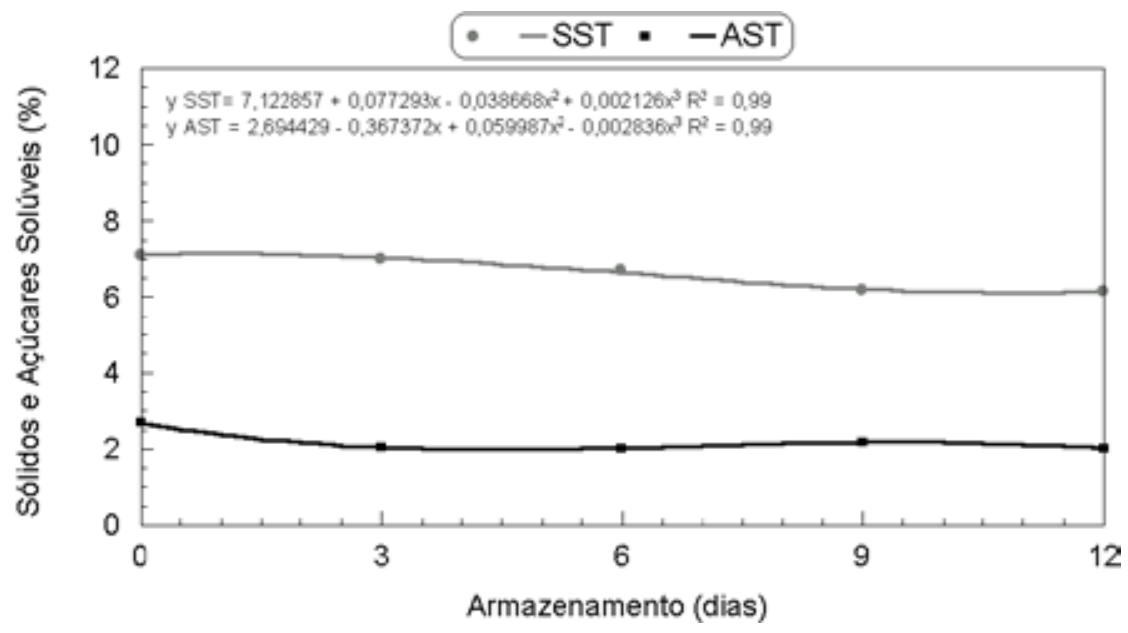

Figura 4. Médias e variações com o armazenamento de sólidos e açúcares solúveis (\%) de frutos de clones de aceroleira recobertos com filme de PVC e armazenados sob refrigeração $\left(10^{\circ} \mathrm{C}\right)$. 
Valores próximos de SST foram encontrados por Ritzinger, Soares Filho e Oliveira (2003) nas variedades Flor branca, Inada, Número 1, Número 52/02 e Okinawa com 7, 6, 8, 7,5 e $7{ }^{\circ}$ Brix, respectivamente. França e Narain (2003), estudando três matrizes de aceroleira em três safras, com frutos em estádios de maturação diferentes, determinaram SST de 6 a 6,2 e 6,1 a $6,5^{\circ}$ Brix, para frutos de vez e maduros. Entretanto, Carpentieri-Pípolo et al. (2002), em análises de três novos cultivares de acerola, UEL 3 - Dominga, UEL 4 - Lígia e UEL 5 - Natália, e Matsuura et al. (2001) encontraram teores superiores de SST variando de 7,2 até 9,2 ${ }^{\circ} \mathrm{Brix}$, e de 6 a $11,6{ }^{\circ} \mathrm{Brix}$ respectivamente, valores estes, dentro da faixa encontrada por Aguiar (2001) de 3,76 a $14,10{ }^{\circ}$ Brix com média de $9,89{ }^{\circ}$ Brix. Carvalho e Manica (1994) determinou variação de SST de 6,9 a 7,19 ${ }^{\circ}$ Brix, em frutos semi-maduros armazenados sob refrigeração por três dias.

Foi observada diminuição dos teores de açúcares solúveis durante o armazenamento, de 2,69 até 2,02 $\%$ (Figura 4). Valores superiores foram encontrados em estudo feito por Alves, Chitarra e Chitarra (1995), com variação de 4,30 a 2,90 \% dos açúcares solúveis, durante 11 dias em frutos de aceroleira armazenados sob refrigeração e atmosfera modificada. Na póscolheita ocorre o processo fisiológico da respiração com modificação dos constituintes nutritivos, em três fases: quebra ou hidrólise de polissacarídeos em açúcares simples; oxidação de açúcares a ácido pirúvico (ciclo glicolítico); transformação aeróbica do ácido pirúvico e outros ácidos orgânicos em $\mathrm{CO}_{2}$ e água (ciclo de Krebs) (CHITARRA; CHITARRA, 2005), que pode ser responsável por esta variação do teor de açúcar durante o armazenamento.

A acidez, maior em frutos verdes, diminui enquanto estes amadurecem. Nos clones Apodi, Cereja e Roxinha essa diminuição foi mais acentuada, enquanto nos demais clones foi inferior, quase estável (Figura 5). De acordo com Chitarra e Chitarra (2005), o teor de ácidos orgânicos, com poucas exceções, diminui com a maturação.

Os valores determinados por Gomes et al. (2000) foram de 3,07 a 3,82\%, próximos aos frutos ainda não maduros, no início do experimento. Enquanto Matsuura et al. (2001), analisando frutos de 12 diferentes genótipos de acerola 'de vez', encontraram acidez total titulável de 0,69 a 1,65 $\%$ de acordo com os determinados neste trabalho em frutos maduros por volta do $6^{\circ}$ e $12^{\circ}$ dia de armazenamento. Aguiar (2001) analisando frutos maduros de aceroleira encontrou variação de 0,89 a 2,1\% de acidez em ácido málico, porém, a maioria dos clones (56\%) produziu frutos acima de 1,3\%, assim como Carvalho e Manica (1994) que em frutos semi-maduros armazenados sob refrigeração por três dias encontrou acidez variando de 1,61 a $1,69 \%$ neste período.

Foi verificada diminuição gradual do $\mathrm{pH}$ durante o armazenamento de todos os clones (Figura 5), o que é um indício da diminuição da acidez dos frutos à medida que ocorre a maturação, independente dos clones, como observado por França e Narain (2003). Nogueira et al. (2002) encontraram valores mais elevados, situados entre 3,36 e 3,49 em frutos maduros; e Carvalho e Manica (1994), avaliando frutos semi-maduros armazenados sob refrigeração por três dias, de 3,49 a 3,36. Resultados mais próximos foram encontrados por Matsuura et al. (2001), analisando frutos de 12 diferentes genótipos de aceroleira 'de vez', encontrando valores de $\mathrm{pH}$ de 3,18 a 3,44 .

A relação SST/ATT aumentou durante o armazenamento devido à diminuição da acidez, como fruto no final do armazenamento apresentando sabor mais adocicado, com relação SST/ATT variando de 3,66 a 5,18 para os clones Cereja e Sertaneja, respectivamente. Vale ressaltar a estabilidade desta característica nos clones Frutacor, II 47/1 e Sertaneja (Figura 5). Valores próximos foram encontrados por França e Narain (2003), pesquisando três matrizes de aceroleira em três safras, com frutos em estádios de maturação diferentes, de 4,35 a 7,82 em frutos “de vez" e 4,73 a 9,42 em frutos maduros, e Matsuura et al. (2001), analisando frutos de 12 diferentes genótipos de acerola 'de vez', de 4,24 a 11,59. Aguiar (2001) determinou relação SST/ATT entre 2,5 e 14,38 com média de 7,52 em frutos maduros de aceroleira. 

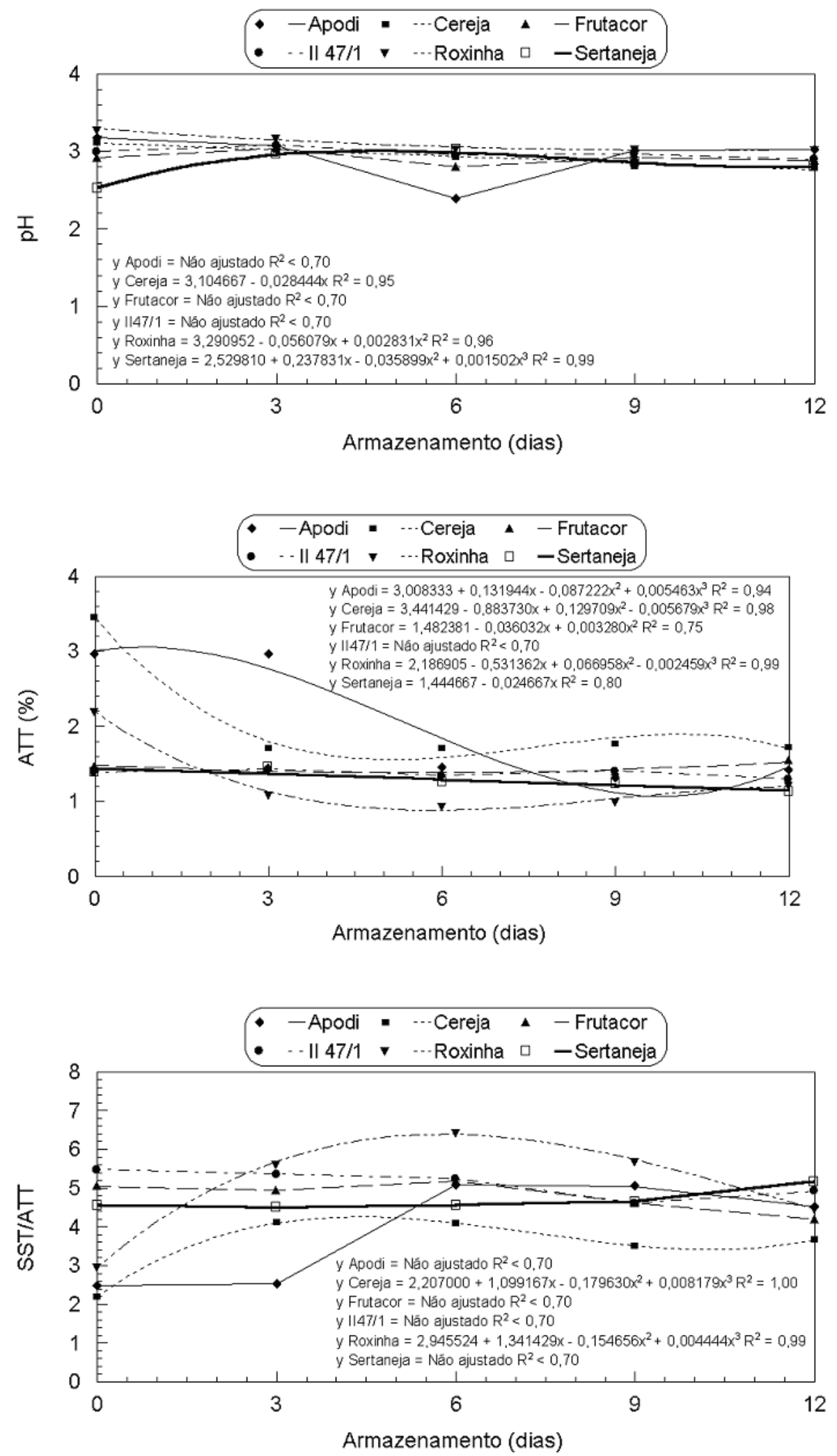

Figura 5. Acidez total titulável (ATT) (\% de ácido málico), pH e relação sólidos solúveis totais/ acidez total titulável (SST/ATT) de frutos de clones de aceroleira recobertos com filme de PVC e armazenados sob refrigeração $\left(10^{\circ} \mathrm{C}\right)$. 
Adiminuição do teor de vitamina C era previsível, pois este nutriente está presente em maiores quantidades nos frutos verdes de acerola. Esse processo talvez seja explicado pela maior atividade da enzima ácido ascórbico oxidase em frutas mais maduras (VENDRAMINI; TRUGO, 2000). Como exemplo, o clone Cereja decresceu seu teor neste nutriente de $2460,28 \mathrm{mg} / 100 \mathrm{~g}$, com frutos iniciando a coloração vermelha, até $1586,16 \mathrm{mg} / 100 \mathrm{~g}$, com frutos maduros e no final do experimento e o II $47 / 1$ de 1869,04 a 839,06 mg/100g (Figura 6). O clone Frutacor apresentou a menor perda, de 18,8\%, após 12 dias de armazenamento, seguido pelo clone Roxinha, que apresentou perda de 28,5\%. Alves, Chitarra e Chitarra (1995) determinou perdas de vitamina $\mathrm{C}$ em frutos de aceroleira armazenados a temperatura ambiente e sob atmosfera modificada, em torno de $38 \%$ em três dias, enquanto os frutos armazenados refrigerados apresentaram perdas de $60 \%$ em 11 dias.

Nos frutos verdes foram encontrados valores médios de vitamina $C$ de 1797,03 mg/100g, inferiores aos determinados por Carpentieri-Pípolo et al. (2002), em análises de três novos cultivares de acerola, UEL 3 - Dominga, UEL 4 - Lígia e UEL 5 - Natália, de 2906 a $3579 \mathrm{mg} / 100 \mathrm{~g}$.

Nogueira et al. (2002) encontraram decréscimo do teor de vitamina $\mathrm{C}$ durante o amadurecimento, de 2732,7 para $1682,67 \mathrm{mg} / 100 \mathrm{~g}$ na estação seca e de 1753,25 até $865,8 \mathrm{mg} / 100 \mathrm{~g}$ na estação chuvosa, de frutos verdes para maduros, respectivamente.

Valores superiores nos frutos maduros foram encontrados por Ritzinger, Soares Filho e Oliveira (2003) de 1500 a $2200 \mathrm{mg} / 100 \mathrm{~g}$ respectivamente, Carpentieri-Pípolo et al. (2002), em análises de três novos cultivares de acerola, UEL 3 - Dominga, UEL 4 - Lígia e UEL 5 - Natália, de 1098 a 1458 mg/100g e Matsuura et al. (2001) de 825 a 1820 mg/100g.

Aguiar (2001) encontrou teores de vitamina C em frutos maduros de aceroleira de experimentos de melhoramento genético localizados em BrasíliaDF, Ibiapina e Pacajus (CE) médios de 1489,73 $\mathrm{mg} / 100 \mathrm{~g}$, variando de 834,03 e $2322 \mathrm{mg} / 100 \mathrm{~g}$.

O clone Frutacor apresentou maior teor de carotenóides dentre os estudados, podendo ser notado pela análise do ângulo Hue, em que se constatou neste clone maiores valores no final do experimento. De um modo geral, os demais clones aumentaram o teor deste pigmento nos primeiros dias do experimento, com conseqüente diminuição. O aumento do teor de carotenóides durante o armazenamento se deveu ao fato de que os frutos de aceroleira foram colhidos no início do amadurecimento. No decorrer do armazenamento ocorreu síntese destes (Figura 6).

Lima et al. (2005) observou aumento na síntese de carotenóides durante o amadurecimento de frutos de aceroleira. Alves et al. (1995) citam que durante a maturação de frutos de aceroleira, o conteúdo de carotenóides aumentou de zero para 1,4 mg/100 g, e que a síntese deste pigmento na acerola continua até $o$ final do amadurecimento ou início da senescência.

$\mathrm{O}$ teor de antocianinas apresentou crescimento gradual durante o armazenamento, provavelmente devido ao amadurecimento dos frutos, o clone II 47/1 passou de 6,13 até $8,12 \mathrm{mg} / 100 \mathrm{~g}$ de antocianinas durante o período do experimento (Figura 6). De acordo com Alves (1996), a coloração comercial da acerola é vermelho-escura, portanto, quanto maior o teor de antocianina, melhor a aceitação do produto, por parte do consumidor.

Lima et al. (2002) encontraram teores de 14,11 a $26,23 \mathrm{mg} / 100 \mathrm{~g}$ em polpas de frutos de aceroleira armazenadas por 180 dias. Superiores foram os teores de antocianinas encontrados por Aguiar (2001) de até $38,38 \mathrm{mg} / 100 \mathrm{~g}$, com média de 13,51 e mínimo de 0,37 mg/100g. Moura et al. (2007), pesquisando clones de aceroleira, encontraram teores de antocianinas variando de 1,81 a 28,47 $\mathrm{mg} / 100 \mathrm{~g}$, com um predomínio de $38 \%$ nas acerolas com valores entre 5,0 e 10,0 mg/100g. Estes autores encontraram clones com valores menores que 5,0 $\mathrm{mg} / 100 \mathrm{~g}$, demonstrando a variabilidade existente também para esse parâmetro. 

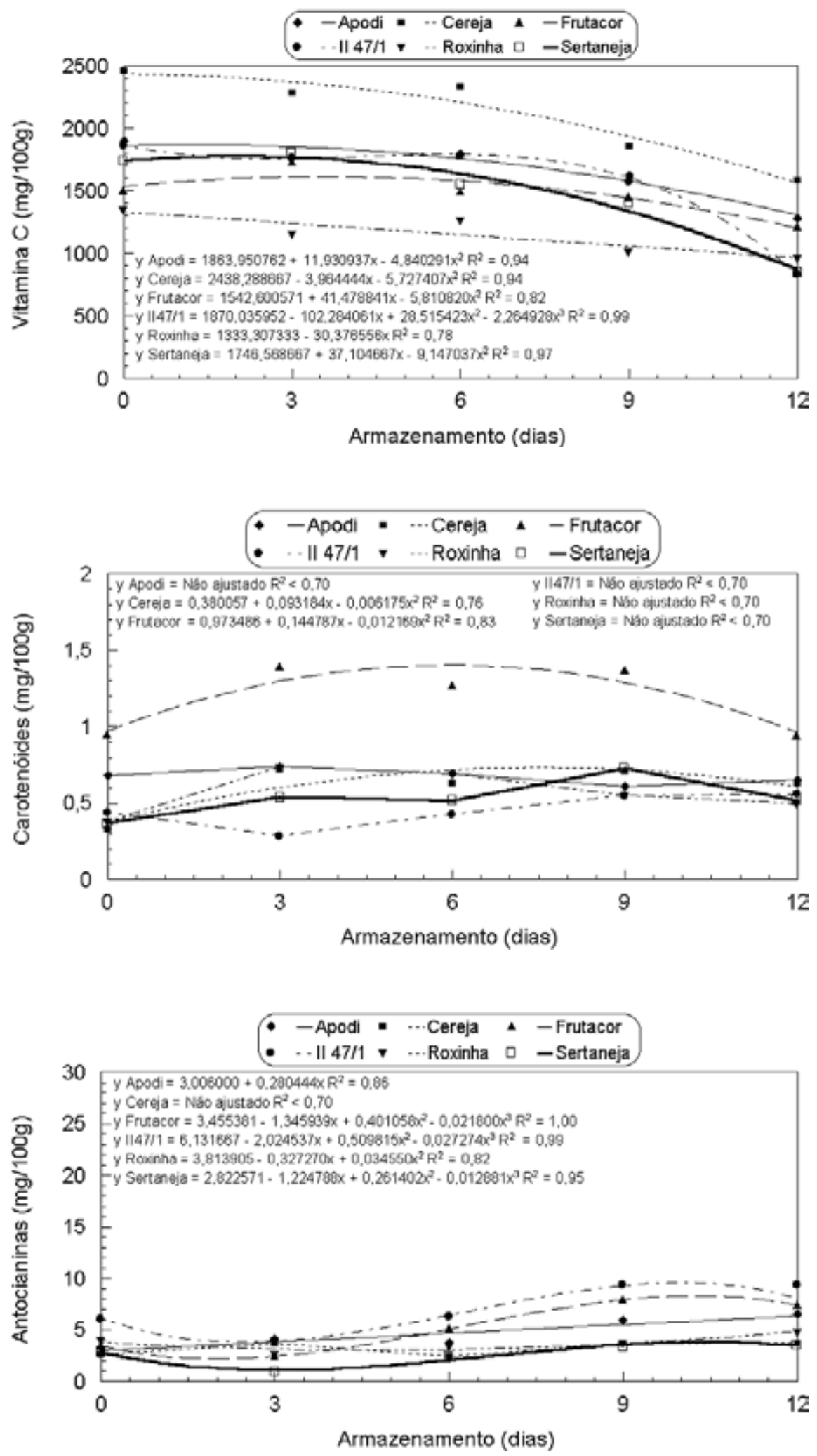

Figura 6. Vitamina C (mg de ácido ascórbico/100g), carotenóides (mg de carotenóides totais/100g) e antocianinas (mg de antocianinas totais/100g) de frutos de clones de aceroleira recobertos com filme de PVC e armazenados sob refrigeração $\left(10^{\circ} \mathrm{C}\right)$. 


\section{Conclusões}

$\mathrm{O}$ clone III4/1 se destacou pela relativa estabilidade da cor, ângulo Hue, e teor de antocianinas, sendo mais atrativa para o consumidor na hora da compra.

O clone Frutacor apresentou maior teor de carotenóides dentre os avaliados.

Os clones Roxinha e Sertaneja apresentaram relação SST/ATT superior aos demais no final do experimento, característica interessante para o sabor.

O clone Cereja foi o que apresentou maior luminosidade no início do experimento, com ligeiro decréscimo ao final deste, enquanto o Sertaneja permaneceu estável.

De um modo geral, todos os clones diminuíram o ângulo Hue durante o armazenamento, com destaque para os clones Cereja e II 47/1.

Verificou-se diminuição de massa, firmeza, acidez, $\mathrm{pH}$, açúcares solúveis e vitamina $\mathrm{C}$ durante $\mathrm{o}$ armazenamento para todos os clones estudados; enquanto os teores de carotenóides e antocianinas apresentaram crescimento gradual.

\section{Referências}

AGUIAR, L. P. $\beta$-caroteno, vitamina $C$ e outras características de qualidade de acerola, caju e melão em utilização no melhoramento genético. 2001. Dissertação (Mestrado em Tecnologia de Alimentos) - Universidade Federal do Ceará, Fortaleza.

ALVES, R. E. Características das frutas para exportação. In: GORGATTI NETTO, A.; GARCIA, E. E.C.; BLEINROTH, E. W.; FREIRE, F. C. O.; MENEZES, J. B.; BORDIM, M. R.; BRAGA SOBRINHO, R.; ALVES, R. E. Acerola para exportação: procedimentos de colheita e pós-colheita. Brasília: Embrapa-SPI, 1996. p. 9-21.

ALVES, R. E.; CHITARRA, A. B.; CHITARRA, M. I. F. Postharvest Physiology of acerola (Malpighia emarginata D.C.) fruits: Maturation changes, respiratory activity and refrigerated storage at ambient and modified atmospheres. Acta Horticulturae, Leuven, v. 370, n. 1, p. 223-229, 1995.
ALVES, R. E.; MOSCA, J. L.; FILGUEIRAS, H. A. C.; PINTO, S. A. A.; MOURA, C. F. H. Armazenamento refrigerado de pedúnculos de cajuieiro anão-precoce CCP76 sob atmosfera modificada. Revista Iberoamericana de Tecnología Postcosecha, Hermosillo, v. 5, n. 1, p. 38-42, 2003.

ASSOCIATION OF OFFICIAL ANALYTICAL CHEMISTRY - AOAC. Official methods of analysis of the Association of Official Analytical Chemistry. 15. ed. Washington, 1995. $2 \mathrm{v}$.

BRASIL. Ministério da Saúde. Agência Nacional de Vigilância Sanitária. Métodos físico-químicos para análise de alimentos. 4. ed. Brasília, DF, 2005.

BRUNINI, M. A.; MACEDO, N. B.; COELHO, C. V.; SIQUIERA, G. F. Caracterização física e química de acerolas provenientes de diferentes regiões de cultivo. Revista Brasileira de Fruticultura, Jaboticabal, v. 26, n. 3, p. 486-489, 2004.

CARPENTIERI-PÍPOLO, V.; PRETE, C. E. C.; GONZALEZ, M. G. NILO.; POPPER, I. O. Novas cultivares de acerola (Malpighia emarginata DC): UEL 3 - Dominga, UEL 4 - Lígia e UEL 5 - Natália. Revista Brasileira de Fruticultura, Jaboticabal, v. 24, n. 1, p. 124-126, 2002.

CARVALHO, R. I. N.; MANICA, I. Influência de estádios de maturação e condições de armazenamento na conservação da acerola (Malpighia glabra L.). Pesquisa Agropecuária Brasileira, Brasília, v. 29, n. 5, p. 681-688, 1994.

CHITARRA, A. B.; CHITARRA, M. I. F. Pós-colheita de frutos e hortaliças: fisiologia e manuseio. 2. ed. Lavras: UFLA, 2005.

FRANÇA, V. C.; NARAIN, N. Caracterização química dos frutos de três matrizes de acerola (Malpighia emarginata D.C.). Ciência e Tecnologia de Alimentos, Campinas, v. 23, n. 2, p. 157-160, 2003.

FRANCIS, F. J. Analysis of anthocyanins. In: MARKAKIS, P. (Ed.). Anthocyanins as food colors. New York: Academic Press, 1982. p. 181-207.

GOMES, J. E.; PERECIN, D.; MARTINS, A. B. G.; ALMEIDA, E. J. Variabilidade fenotípica em genótipos de acerola. Pesquisa Agropecuária Brasileira, Brasília, v. 35 , n. 11, p. 2205-2211, 2000.

GUADARRAMA-G, A. S. Alguns cambios químicos durante la maduracion de frutos de semeruco (Malpighia punicifolia L.). Revista de la Faculdad de Agronomia, Maracay, v. 13, p. 111-139, 1984. 
HIGBY, W. K. A simplified method for determination of some the carotenoid distribution in natural and carotenefortified orange juice. Journal of Food Science, Chicago, v. 27 , n. 1, p. 42-49, 1962.

LIMA, V. L. A. G.; MÉLO, E. A.; LIMA, L. S.; LIMA, D. E. S. Polpa congelada de acerola: efeito da temperatura sobre os teores de antocianinas e flavonóis totais. Revista Brasileira de Fruticultura, Jaboticabal, v. 24, n. 3, p. 669-670, 2002.

LIMA, V. L. A. G.; MELO, E. A.; MACIEL, M. I. S.; PRAZERES, F.G.; MUSSER, R.S.; LIMA, D.E.S. Total phenolic and carotenoid contents in acerola genotypes harvested at three ripening stages. Food Chemistry, London, , v. 90, n. 4, p. 565-568, 2005.

MACIEL, M. I. S.; LIMA, V. L. A. G.; SANTOS, E. S.; LIMA, M. S. Effects of biofilm and refrigeration on acerola postharvest conservation. Revista Brasileira de Fruticultura, Jaboticabal, v. 26, n. 1, p. 168-170, 2004.

MATSUURA, F. C. A. U.; CARDOSO, R. L.; FOLEGATTI, M. I. S.; OLIVEIRA, J. R. P.; OLIVEIRA, J. A. B.; SANTOS, D. B. Avaliações físico-químicas em frutos de diferentes genótipos de acerola (Malpighia punicifolia D.C.). Revista Brasileira de Fruticultura, Jaboticabal, v. 23, n. 3, p. 602-606, 2001.

MOURA, C. F. H.; ALVES, R. E.; PAIVA, J. R.; FIGUEIREDO, R. W.; FILGUEIRAS, H. A. C.; QUEIROZ, D. L. Avaliações físicas e físico-químicas de frutos de clones de aceroleira (Malpighia emarginata D.C.). Ciência Agronômica, Fortaleza, v. 38, n. 1, p. 5257, 2007.
NOGUEIRA, R. J. M. C.; MORAES, J. A. P. V.; BURITY, H. A.; SILVA JUNIOR, J. F. Efeito do estádio de maturação dos frutos nas características físico-químicas de acerola. Pesquisa Agropecuária Brasileira, Brasília, v. 37, n. 4, p. 463-470, 2002.

PAIVA, J. R. ALVES, R. E.; SANTOS, F. J. S.; BARROS, L. M.; ALMEIDA, A. S.; MOURA, C. F. H.; CACAU, J. B.; NORÕES, N. P. Seleção preliminar de clones de aceroleira no estado do Ceará. Ciência e Agrotecnologia, Lavras, v. 27, n. 5, p. 1038-1044, 2003.

REINHARDT, D. H.; OLIVEIRA, J. R. P. Manejo póscolheita. In: RITZINGER, R.; KOBAYASHI, A. K.; OLIVEIRA, J. R. P. A cultura da acerola. Cruz das Almas: Embrapa Mandioca e Fruticultura, 2003. p. 150163.

RITZINGER, R.; SOARES FILHO, W. S.; OLIVEIRA, J. R. P. Variedades e Melhoramento. In: RITZINGER, R.; KOBAYASHI, A. K.; OLIVEIRA, J. R. P. A cultura da acerola. Cruz das Almas: Embrapa Mandioca e Fruticultura, 2003. p. 65-72.

VENDRAMINI, A. L.; TRUGO, L. C. Chemical composition of acerola fruit (Malpighia glabra L.) at three stages of maturity. Food Chemistry, London, v. 71, n. 2, p. 195-198, 2000.

YEMN, E. W., WILLIS, A. J. The estimation of carbohydrate in plant extracts by anthrone. The Biochemical Journal, London, v. 57, n. 2, p. 508-514, 1954. 